\title{
BLICKDIAGNOSE-QUIZ
}

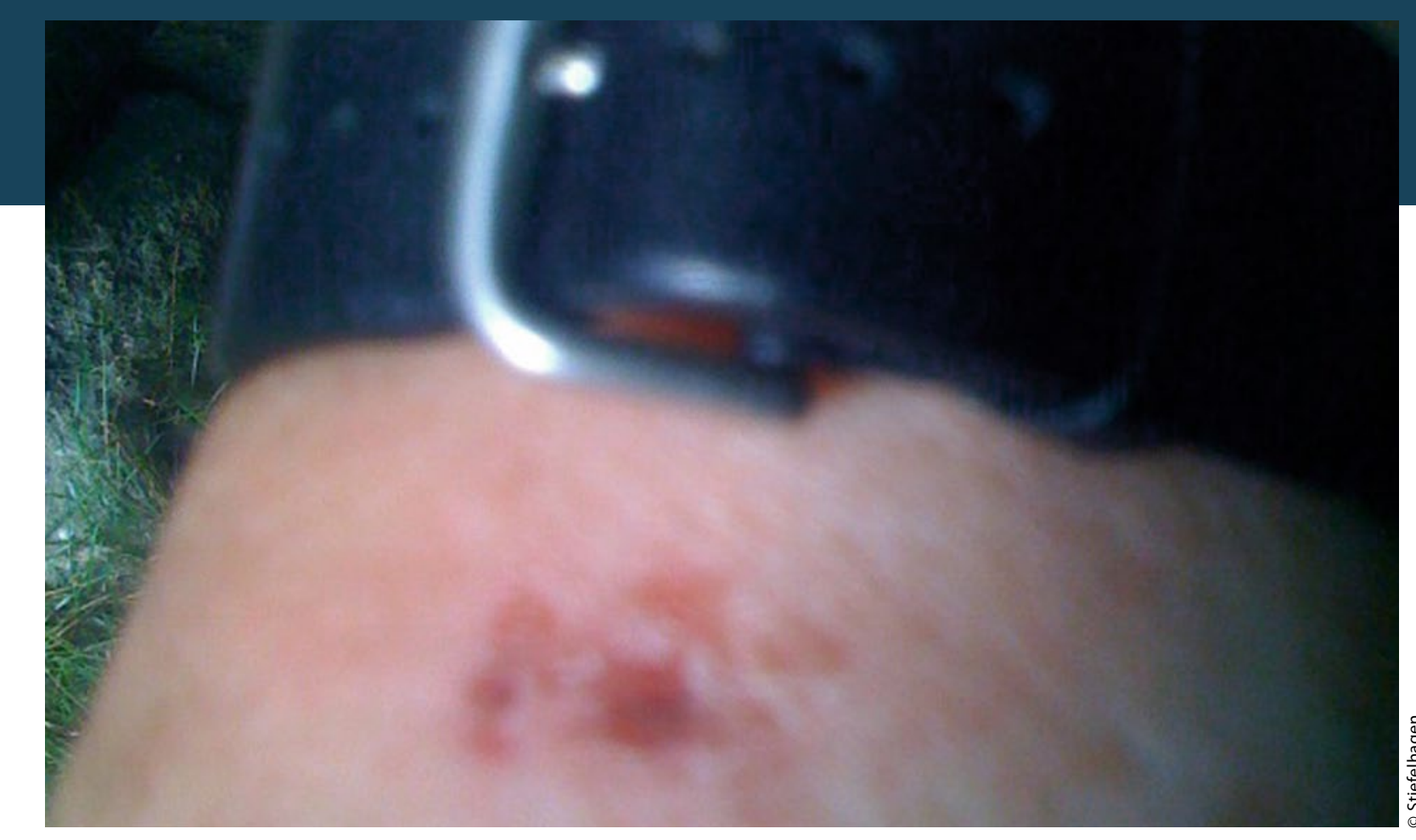

Juckende Bläschen am Unterarm

\section{Aber immer nur im Sommer!}

— Ein 24-jähriger Patient gibt an, dass seit einigen Wochen immer wieder an derselben Hautstelle, nämlich an der Innenseite des distalen Unterarms nahe des Handgelenks, eine umschriebene juckende Rötung mit anschließender Bläschenbildung auftrete. Wenn er die Uhr weglasse, bildeten sich die Hautveränderungen innerhalb weniger Tage vollständig zurück. Wenn er die Uhr dann wieder trage, beginne das Spiel von vorne.

Die Effloreszenz sei bereits im Sommer des vergangenen Jahres mehrmals in leichterer Form an derselben Stelle aufgetreten. In der kühleren Jahreszeit von Oktober bis Mai habe er aber Ruhe gehabt. Er habe die Uhr versuchsweise auch einmal am anderen Arm getragen. Dort seien dann die gleichen Hautveränderungen aufgetreten.
Wie lautet die Diagnose:

A) umschriebener Sonnenbrand,

B) Pilzinfektion,

C) allergisches Kontaktekzem i. S. einer Nickelallergie,

D) Druckulkus?

\section{Auflösung S. 25}

- Dr.med. Peter Stiefelhagen,

Westerwaldklinik, D-57627 Hachenburg

\section{Weitere Infos auf springermedizin.de}

Weitere Fälle unserer Leser finden Sie im Internet unter: - www.springermedizin.de/blickdiagnose 